\title{
Diversity Management in the Campania Region (Italy): A Case Study
}

Francesco lovine

Doi:10.5901/mjss.2015.v6n2s5p128

francescoivn@hotmail.it

\section{Abstract}

This contribution revolves around the main topics regarding the impact of gender on the culture of organization. The specific objective is exploring the organizational context and the working conditions within good examples of Diversity Management. The research, in fact, aims at developing a model of knowledge that is useful to re-think the existing forms of flexicurity with the purpose of increasing female occupation and promoting sustainable territory development. All of this thought in the perspective of spreading the culture of Diversity Management and having an effect on social and working inclusion of women and young graduates, especially in the field of cooperative enterprises. For such a purpose, a case study on Diversity Management is shown with the goal of analyzing organizational models including young female entrepreneurs as protagonists that are active in Campania, a region of southern Italy in which the University of Salerno operates.

Keywords: Diversity Management, Campania Region, female occupation, promoting sustainable territory development

\section{Introduction}

This paper presents the first results of a an extensive research on diversity management, which includes case studies, finalized to analyze virtuous models of female entrepreneurship that are present in particular in the territory of Campania, the region of southern Italy in which the University of Salerno is located.

As a starting point, we have launched a first survey on a company having educational purposes, "Crescere Insieme", working in Mercato San Severino (SA). It has been founded by two young women, Alfonsina and Rosa, who have both graduated in Educational Sciences at the University of Studies of Salerno.

For simpler reading, information related to the company are summarized in the grid below.

\begin{tabular}{|l|l|l|}
\hline General information & Crescere Insieme & \\
\hline Company name & $\begin{array}{l}\text { via Trieste 49, 84085 Mercato San } \\
\text { Severino (SA) }\end{array}$ & $\begin{array}{l}\text { Tel. } 089890441 \\
\text { Cell. 3331640306 }\end{array}$ \\
\hline Address & www. asilonidocrescereinsieme. it & \\
\hline Website & Alfonsina Della Rocca, Rosa Santoro & $\begin{array}{l}\text { Age at the start of company activities: both } 26 . \\
\text { Qualifications: Degree in Educational Sciences for both. }\end{array}$ \\
\hline Founder members and managers & $\begin{array}{l}\text { First opening 8th of July 2011; Start } \\
\text { of activities 11th of July 2011 }\end{array}$ & \\
\hline Start of activities & $\begin{array}{l}\text { Monday: 7: 40 - 18: 30 } \\
\text { Saturday: 8: 00 - 12: 00 }\end{array}$ & \\
\hline Hours open to the public & 100 & \\
\hline Number of users (male and female children) & & \\
\hline Educational services offered & & \\
\hline Nursery & & \\
\hline Maternal school & For children attending primary school & \\
\hline Playroom & and first level secondary school & \\
\hline Parties and animation & & \\
\hline Mess hall & & \\
\hline Afterschool activities & Friday from 8. 00am to 5. 00pm. & \\
\hline Laboratories & For children attending the nursery \\
\hline English courses for children & $\begin{array}{l}\text { and maternal school, as well as } \\
\text { users of the mess hall and } \\
\text { afterschool activities. }\end{array}$ & \\
\hline Baby parking & & \\
\hline Summer camp & & \\
\hline Pediatric guidance & & \\
\hline Psychopedagogy guidance & & \\
\hline Coach service & & \\
\hline
\end{tabular}




\section{From Idea to Project}

Alfonsina's tale of the various steps which have led to the birth of the Educational Centre offers food for thought. From the very way in which the project was conceived interesting elements emerge about the modus operandi of the young entrepreneur:

"This idea was born a bit before my degree [...] my friend and I thought we would create something of our own, so to set up a kindergarten, a kindergarten because in our area, we evaluated, there were no such facilities so we thought we would start a business of our own. [...] We noticed that the facilities already working [in our area] were simply playrooms [...] there were no kindergartens in our area and so we thought [...] we would start this business, I mean, because there was a demand".

The idea to start a business of their own, which matured before the end of their education, has then evolved into a project. Such a project was developed joining market demands and personal aspirations. This last aspect was the prevailing factor for motivation. In fact, this initiative sprouted from the personal desire shared by both of them to work in children education:

"We like the kindergarten branch, the maternal school branch, of course we have only evaluated this branch, I mean, because since we're studying Educational Sciences, that is since we study in this very field, by going in various traineeships we realized it is what we wanted to do and so we did surveys related to this branch."

To overcome the lack of experience, the two young entrepreneurs gathered information from experts of various fields, from public institutions to private subjects, in order to draw a clear picture of how to get ahead and make their project a reality. Their statements reveal an active approach, a strong will but also the openmindedness to confront other people and acquire knowledge on all aspects of their business:

"In the beginning we talked about it with competent people then [...] with people already having such a facility, of course not in this area, but in others, then we talked about it with our mayor, with some of the members of his council, with the ASL (Local Health Companies) and other people like our accountant, some lawyers, to get a rough idea of how to create this facility and get some directions [...] then anyway, since we didn't have great economic resources to do this thing, we tried to understand how to get some help, some funding to start this business. "

\section{The Courage to Get in the Game}

Good intentions aside, economic resources were needed to sustain the investment. For this reason, the two girls decided to ask for a loan of 70.000 euros to Invitalia, the National Agency for Attracting Investments and Company Development. They did not succeed at first try. Nevertheless, Alfonsina and Rosa were not brought down by that and improved their project then reapplied the following year:

\footnotetext{
"The first time it was rejected, the second time it was accepted. Of course, we had an interview and after this interview we were answered positively. [...] We showed our whole project again, starting from what facility we wanted to create, what personnel to employ in this facility, so all the activities we wanted to do and why we had chosen this thing. [...] After an evaluation Invitalia called us for an interview and during this interview it asked us a lot of questions on this project of ours. [...] After the interview they replied after a couple months. After this we basically came back there to put our signatures on everything, the contract and all that and then we started to build up I mean we started going to suppliers to do invoices, to call the company which took care of refurbishments, we restructured the premises, to fill in the due forms at the town hall of Mercato San Severino (SA) and then little by little it came out...".
}

Once the red tape had been dealt with, the premises had to be rented and restructured, furniture had to be put in and everything necessary had to be done. The loan of 70.000 euros, half lump sum and half to be given back in 5 years with an interest of $1 \%$ - so not 35.000 but 41.000 euros - was supplied in various instalments.

"They give you the money when you have a payment, a check, a money transfer which proves the existence of the payment to the suppliers, generally. [...] They wouldn't give you this money right away. They basically gave them in various instalments. We had to pay in advance for everything and later we were reimbursed. [...] Then they came to the premises to control whether all we had declared had been done or not. [...] In the end we are going to pay back 41 thousand euros, because it's half of it plus interest, but in five years so until 2018, in tri-monthly investments". 


\section{The Family Support}

An element not to be underestimated in this story is family support, be it material or moral. Alfonsina stresses that the loan Invitalia agreed on was supplied in investments that could only reimburse expenses that had already been made. Therefore, notwithstanding the funding, a starting capital was needed.

"Family was always there, always agreeing, I mean they had faith in what we were going to create [...] friends too, but sometimes they didn't even realize all that we were doing, so, in the end, when we opened [...] they congratulated us for this thing. [...] Family supported us economically for starters, because other than the funding we had to spend some of our own money because the sum we had applied for wasn't enough to get the job done anyway, to create all of this facility. So they gave us a big hand economically for starters, then they stayed close to us, they helped us economically throughout our journey. They (also) did hands-on work where cleaning was needed [...] during the opening [...] they are still there today and help us with this thing. "

\section{Youth and Gender between Prejudice and Stereotypes}

Alfonsina says that throughout the various steps that eventually led to the birth of their company, her partner and her met an ambivalent attitude in the various characters they have met since 2011 to present day.

About the specific purpose of their activity, children's education, nobody argued with them: in fact, being women they were believed to have an actual advantage in the field of education.

For what regards, instead, their young age, this was seen as a setback by the various characters the young entrepreneurs had to deal with. First, bureaucratic institutions tried to undermine the initiative by making known that they saw youth as a limit. More specifically, the ASL (Local Health Company - regional public entity embodying National Health Service) personnel in charge of verifying the required documentation attesting that the health norms had been respected tried to convince the girls to give up on realizing such a complex activity from the very start.

"Because we were women [...] anyway it's an activity we [...] as women can carry out well enough, so they had no problems with that; about our young age somebody doubted that we could manage a company like this, a facility hosting 100 children so somebody was a bit doubtful. In the beginning of our project some people even said: - you are taking a risk, you are creating a very big project, what about maybe doing something simpler, don't throw yourself blindly in this important thing -. Some people, as we asked them information or guidance on this thing, they said: - you shouldn't be doing that, don't do this thing, do something smaller, something more limited-.

I'm talking about people [...] at the ASL. Regarding the town hall, the mayor has always given us freedom, has never limited us in anything, has always given us freedom to do this thing [...], he has always believed in in this thing and always believed in us, in short, he has never been an obstacle".

The effort required for such an activity, according to the prejudice the girls met, would be out of reach for two girls this young. The advice they were given was to give up on such an ambitious and complex project, to start from something simpler. These attempts, by the way, did not discourage the two educators-entrepreneurs, but were instead interpreted as incentive, as a challenge to prove how relevant passion and vocation can be. These two last aspects are the strong points by which external pressures were endured. It was thanks to hard work and achieved results that the two young girls have managed to prove even their harshest critics wrong. What Alfonsina and Rosa are proud to have demonstrated is that youth is not a limit but a resource that, if adequately used, can give the strength to make one's wishes come true.

The same skepticism about the managing abilities of the two young entrepreneurs was expressed even by some user-mothers, who entering the facility with the intention of signing their children up were perplexed by the owners' young age. Such doubts were made openly known with questions such as: "you're so young, are you sure you can manage all these children?", or "you know there is work to come, you're so young and still you already want to work every day, for all this time?", and also "do you know that dealing with parents is by all means a hard thing to do?"

Notwithstanding this external pressure, not only did Alfonsina and Rosa fulfil their ambition, but with years they also extended the range of services offered and enlarged the very premises, to face an increasing demand.

"At the start we started with 15 children, today we have [...] (about) 80-100 children [...] (and] our services let's say have been extended. I mean we tried to offer new things also. For example [...] the first year we were a private maternal school (childhood school) then we asked to get the status of comprehensive and now we are a comprehensive maternal school (childhood school). Then other than this we have extended our range of services, meaning that as of today we also have a coach service [...]. We bought a coach last year and we have offered coach service since January. For children coming from the province of Avellino, that is from Montoro [Inferiore (SA)] and so in the morning they come with us, we go to their homes and pick them up [...] and also children coming to our kindergarten from home [...] and also we 
pick up children as soon as they come out of school, elementary school (primary school) and first level secondary school, and who come to us for our mess hall and afterschool services. In addition to that, we organize birthday parties, by the way our services have extended because the demand has risen. Actually, we have also made our premises larger to face all the requests we were having. We have extended its surface by other $100 \mathrm{~m}^{2}$ square meters. It currently covers 600 $\mathrm{m}^{2}$."

Age was a weakness to suppliers too, who were unfair in inflating their prices trying to take advantage of the alleged inexperience of the two young women. However, thanks to the guidance of experts, the two owners were able to avoid various attempts to fraud them.

\section{Female Gender as a Guarantee in Education}

The children's fathers, as opposed to mothers, have showed trust in the educational qualities of Alfonsina and Rosa right from the start. We can assume that some known stereotypes regarding female gender according to which childcare and education are natural tasks of women had a final say in it.

Another type of prejudice we can notice in the critical attitude of mothers, who felt challenged as mothers and as elder women, and as such more expert in childcare and education.

Nevertheless, this initial element of competition did not make for an invincible obstacle.

Against such prejudice, the two young educators have managed to reassure the worried mothers by answering their critics with the efficacy of their effort. In such a way they have proven that passion, goodwill to improve, experience acquired in traineeships and a course of study in the pedagogic field are strong points that can make them apt and able to manage the delicate and difficult activity they had chosen to take forward.

"The (our) reply was [...] that for starters age does not matter, passport age at least, meaning that experience as well as willingness to do, to learn and work, those do count I mean, and by the way we are confident about what we have learned, want to do and do, so in the end this activity does not scare us.

About the fathers [...] they complimented us, the mothers instead many times [...] they believe we are too young for this thing, but then [...] after a positive feedback [...] in the end they changed their mind and today they respect us. [...] On the other hand there's another group of mothers who [...] believe [our young age] to be a selling point because we have the energy to work, because being young means we have different perspectives, different projects than those an elder person would have."

\section{An Organizational Model Based on Assertiveness, Cooperation and Flexibility}

The business model adopted within "Crescere Insieme" was not the product of a rigid pre-existing idea the two aspiring entrepreneurs had, but matured following actual experience on the field, other than the willingness to learn, through educational models of cooperation and work.

"Before the opening, my partner went on traineeships also to understand how to run a business like this. Then little by little we were helped by accountants, lawyers, work consultants who walk us through these things. A selling point is also that I, aside from a degree in Educational Sciences, also have a diploma in accounting and as such I'm able to manage the bureaucratic part of the company. On the other hand, my partner [Rosa] is also a major in Educational Sciences and having under our belts traineeships we did together in various kindergartens we have managed to sort it all out... the bureaucratic part on my shoulders mainly, the managing part regarding children class management, parents management and personnel management on hers instead. Of course a big help has come from these people guiding us, walking us through. What also helped was experience: after four years of experience we are able to better manage the situations we are presented".

The willingness to get better and openness to criticism did not run out in the initial phase, since as of now the girls are continuing to ask various professionals for advice. The pilot survey and the internship in similar companies have been useful as a way to approach the field. Yet, the organizational model only matured afterwards following the different personal and professional skills.

In fact, the organizational formula the two owners adopted consists of a role division based on personal resources and professional background of each of them. Alfonsina copes with bureaucratic matters, while Rosa deals with the public relations with personnel, parents and children. Nevertheless, their work is not done after the general coordination and administrative tasks have been carried out, but is also made of fieldwork: manager responsibilities do not stop them from working as educators themselves. Even in this sense, a further division of roles ensues: Alfonsina is in charge of the nursery, hosting children from 0 to 3 years of age, while Rosa cares for childhood education for children from 3 to 5 
years.

Regarding relationship and communication model, the basic ideology behind "Crescere Insieme" is about perceiving themselves as "a family". This is especially true in relations with the personnel working in education: among the members of this family, owners included, there are no hierarchies, let alone an authoritative principle marking the relationship. The secret sauce to get better at one's job, according to the way Alfonsina sees it, is being open to constructive discussion and speak to each other with sincerity and serenity.

Speaking about relations with the children's parents, in this sense also the main idea is adopting a not-toodetached or professional-looking attitude. Dialog is built on some ingredients that are considered essential: loyalty and sincerity. As soon as a problem or situation requiring special attention shows up, i. e. a child showing disruptive behavior or the arisen suspicion of a learning impairment or other psycho-somatic deficiency, a professional opinion is given to parents, but all is done in the general climate of mutual cooperation, in order not to burden the family with a final diagnosis or a rigid solution.

"If we speak about wrong attitude [...] in class [...] we immediately report to parents because we believe that school and family must collaborate and cooperate anyway, so in the end we think a parent should be informed of such things. We simply tell him [...] we always get in these terms, I mean we inform the parents of their child's attitude in class and of what we may think about that, then of course we don't take decisions, it's the parent's responsibility to decide the course of action.

[Then again] it depends on situation, it depends on what happened, it depends on the parents you are dealing with because for each parents you have to adopt a different methodology [...]. Still we always try to get on their level [...] we try to inform them in a very relaxed way. [...] We look for cooperation, that's it, so inform them in order to find a solution together. It depends then because staying in contact with parents means you are able to understand each parent and for each you select a different approach".

According to Alfonsina's point of view, flexibility and the ability to adapt to people and context is a key point for a correct educational intervention. The parents' situation must be taken into consideration depending on who you deal with, after which you try to negotiate a possible common educational strategy. In this sense, you try to stimulate the family into being more and more capable to make self-analysis.

This horizontal and cooperative relationship model also encompasses relations with personnel, which in turn are based on giving value to each one's skills and on constructive confrontation.

For every problem that arises you try to discuss together to find the best solution depending on case.

Because of that, internal hierarchies regulating interactions among employers and employees do not exist. From the moment they are employed, all educators are told:

"we're a family here. [...] We have never said: - we're the bosses and you're the employees -, or things such as: we're the owners. We always get on equal level, we have never said: - I'm the owner and you will do what I say - or similar things. Hierarchies do not exist here, we're all the same, in the same way. [Although there were] arguments which might have brought to an educator or teachers leaving, [...] most of our discussions [are aimed at] improving ourselves [...] constructive criticism is done".

\section{From Kindergarten to Kindergarten: A Tale of Friendship}

The cornerstone the whole project has been built on is the strong bonds of friendship joining the two co-founders together, a relationship going back to the times when they attended kindergarten together.

The idea of creating this facility came from the desire to make something together, before they finished their University studies, which were another shared experience.

"Aside from the fact that it's a bond going strong since our childhood, so in the end today we're both 29 and we've known each other for 29 years. It's obvious that as in any company, in any relationship discussions have to be had, but they're discussions we have in order to find a solution together, not discussions leading to arguments or damage, absolutely not. When the end comes, everything is just the way it used to be, a good solution for both is found and that is that. [...] We have separate [roles], each of us deals with a branch, I deal with the nursery, she [Rosa] deals with maternal school (childhood school), then in the end let's say we discuss, then each deals with her own branch. Then perhaps for what regards choosing how to handle an even, on how to manage personnel, work hours, various things in short, we might have different ideas on something, then we discuss it and get to a solution that meets the needs of both. In the end we almost always agree on $90 \%$ of things, I mean we almost always think the same way, so finding a solution is always easy, so we have never found it difficult to solve anything".

The strong harmony between them has made company management clear of critical conflict, as of today. There 
have never been times of misunderstanding or resentment between the two. Every confrontation has been made with the aim of doing what is right and to the benefit of the educational company, putting selfishness and personal claims aside.

"In the end it's a delicate relationship meaning you always have to keep the balance and so if you can keep the balance then you go forward and work well, otherwise, no, I mean [...] you always have to keep in mind you can't be the only one to decide, you always have to confront to another person and you must be open to thoughts, opinions that other person has, you can't do everything by yourself, yes so you have to discuss [...] about anything. I know having a company is difficult, a work relationship in this sense, yet as we speak we have never had these difficulties because there is just this sincerity-based relationship, this trust-based relationship coming from both of us and I also think the important thing is that we have a shared goal".

\section{Some Thoughts}

This first part of our observation on "Crescere Insieme" showed virtuous aspects on various levels. On the level of approach, the stereotype implying lack of assertiveness in women has been defeated. On the contrary, all the various phases that have led to the realization of the project, and to its more than positive development, have been handled with rationality, determination and a professional approach.

Human resources, in the sense of personality-driven factors, coming from willpower and personal vocation, have constituted the funding element. The way in which to carry out the chosen mission has been chosen considering personal skills. The ability to form relationships has been extended to relations with all the players, vertically as well as horizontally. In building rapport with parents as well as with employers and between partners, symmetric communicative exchanges are preferred which are based on sincerity, loyalty, the right amount of emotional involvement and the ability to communicate in an effective way.

The role and task division sprouting from such a model shows itself able to employ everyone's resources in the best way possible. The follow-up to this research will furtherly investigate this model in order to better analyze not only its strong points and weaknesses but above all discover the factors that make it a model characterized by gender, as stated in our starting hypothesis.

For what regards the overcoming of prejudice and stereotypes connected to gender and age, we have covered that already, but this aspect will also be furtherly and more closely analyzed with a focus on relationships with families and the surrounding environment.

Qualitative interviews will be had with a significative number of subjects involved, and participating observation will be done as well.

\section{References}

Anchisi R. , Gambotto Dessy, M. (1995), Non solo comunicare. Teoria e pratica del comportamento assertivo, Torino, Libreria Cortina. Balbo, L. (2008), Il lavoro e la cura, Torino, Einaudi.

Balbo, L. (ed. ) (2013), Imparare, sbagliare, vivere. Storie di Lifelong Learning, Milano, Franco Angeli.

Bateson, M. C. (1992), Comporre una vita, Milano, Feltrinelli.

Bonazzi, G. (2007), Storia del pensiero organizzativo, vol. 1, FrancoAngeli, Milano.

Dwyer, S. , Richard, O. , \& Chadwyck, K. , (2003), Gender diversity in management and firm performance: the influence of growth orientation and organizational culture, in "Journal of Business Research", Dec. , Vol. 56 Issue 12.

Mapelli, B. , Ulivieri Stiozzi, S. (eds) (2012), Uomini in educazione, Stripes, Rho (MI);

Milani, P. , Pegoraro, E. , L'intervista nei contesti socio-educativi, Una guida pratica, Carocci, Roma, 2011.

Nussbaum, M. C. (2000), Women and Human Development: the Capabilities Approach, Cambridge, Cambridge University Press.

Nussbaum, M. C. (2012), Creare capacità. Liberarsi dalla dittatura del Pil, Bologna, il Mulino.

Selvaggio, M. A. (ed. ) (2013), Educatrici di società. Racconti di donne e di cura, Napoli, ESA.

Sen, A. K. (1985), Commodities and Capabilities, Oxford, Elsevier Science Publishers.

Sennett, R. (2012), Insieme. Rituali, piaceri, politiche della collaborazione, Feltrinelli, Milano, 2012. 